Nuñez, Pedro: (2013) La politica en la escuela: Jóvenes, Justicia y derechos en el espacio escolar. Páginas 283286 en Revista de LA Escuela de CienCIAS de La EduCACIÓN, AÑo 11, Número 10, enero a diciembre DE 2015. ISSN 1851-6297. ISSN EN LINEA 2362-3349.

\title{
NUÑEZ, PEDRO: (2013) LA POLÍTICA EN LA ESCUELA: JÓVENES, JUSTICIA Y DERECHOS EN EL ESPACIO ESCOLAR (1)
}

\author{
Por Diego Beretta* \\ Universidad Nacional de Rosario, Argentina. \\ diegoberre@yahoo.com \\ Por Fernando Laredo** \\ Universidad Nacional de Rosario, Argentina. \\ laredofernando@gmail.com
}

Recibido: 30/06/2014 Aceptado: 31/07/2014

"La política en la escuela", es un libro que contribuye a pensar dialógicamente la política, las formas de ser joven y el ámbito escolar en la contemporaneidad. Contribución original e innovadora ya que no es sencilla misión vincular las relaciones entre diferentes matrices socioculturales que en ocasiones distan tanto que complejiza su encuentro. En este sentido, el material presentado invita a los lectores a interrogarse en dos direcciones. Por un lado, el rol que juega la participación política en el "transitar" la escuela; mientras que por el otro, si el ámbito escolar orienta y en qué manera al proceso de politización juvenil.

El trabajo se caracteriza por recuperar una gran cuantum de estudios e investigaciones que recorren desde aspectos teóricos como de evidencias empíricas provenientes de disciplinas como la Ciencia Política, las ciencias de la educación, la sociología y la antropología. Incluso el autor formó parte de

\footnotetext{
- Lic. en Ciencia Política y Magister en Gestión Pública. Docente de Trabajo Social, Organización y Gestión Institucional en la Licenciatura de Trabajo Social de la Facultad de Ciencias Jurídicas y Sociales de la UNL. Responsable del seminario "Juventudes y Políticas de Juventud" e integrante de la cátedra Política Social I de la Facultad de Ciencia Política y Relaciones Internacionales (UNR).

** Maestrando en Comunicación Estratégica, y Lic. en Periodismo (UNR). Docente adscripto del Seminario "Juventudes y Políticas de Juventud" de la Facultad de Ciencia Política y Relaciones Internacionales (UNR). Docente adjunto Seminario Integración Universidad Abierta Interamericana.
} 
Revista de la Escuela de Ciencias de la Educación, año 11, número 10, enero a diciembre de 2015. Páginas 283-286. ISSN 1851-6297. ISSN en LINEA 2362-3349. Nuñez, PedRo: (2013) La Política en LA ESCUELA: JÓVENES, JuSticia Y derechos en el espacio escolar. Diego Beretta - Fernando Laredo

algunas de ellas, reconociendo el proceso de construcción de conocimiento como incremental, sin desmerecer y sin desconocer lo ya producido, y orientando la investigación fundamentalmente a los aspectos menos indagados acerca de la cuestión.

Pedro Nuñez nos acerca una propuesta provocadora, con el foco situado en un ámbito que lejos de ser en el imaginario actual prístino, es aún un reducto supuestamente cercado de los pulsos de la sociedad moderna, replegado en sus procesos, rutinas y objetivos a formar ciudadanos críticos con las capacidades necesarias para desempeñarse en el mundo adulto. Mirada adulta que pretende preparar a estos inocentes jóvenes para una vida compleja y dura como lo es el trabajo y la responsabilidad familiar.

En ese contexto, para quienes habitan cotidianamente esas instituciones tan caras al Estado y nuestra sociedad, no significa ningún hallazgo encontrar un trabajo que refiera a la presencia de la política en ellas. Reconocen que los jóvenes organizados o no, tienen ideas y elecciones concretas, coordinan acciones en relación a la vida interna o incluso refieren adscripción a espacios políticos tradicionales por fuera de la misma. Lo que si representa un señalamiento no suficientemente estudiado es la forma y la dispar aceptación de que en la escuela, justamente, exista política.

Y es desde esta conjunción que se presenta el trabajo: un espacio -la escuela- un grupo -los/as jóvenes- y un modo -la práctica política-. Y aquí se presenta una tensión central; la necesidad de poner en diálogo categorías habitualmente en desencuentros, como el joven y el alumno. En este aspecto el/la lector/ra encontrará uno de los rasgos más atractivos del trabajo. De este modo, representa también un aporte a la discusión no sólo de las cuestiones juveniles sino a uno de los puentes más transitados entre mundos, la escuela secundaria.

El autor reniega de la repetidamente diagnosticada "pérdida de sentido de la escuela" -violencia escolar, los jóvenes ya no se forman en el interior de ella, no se forman ciudadanos, entre otras-. Se corre de ese diagnóstico justamente porque obstaculiza la posible comprensión de lo que efectivamente sucede en la escuela, de hecho el reflexionar en torno al sentido que los propios jóvenes le dan al estar en el espacio escolar.

¿Desencuentro? ¿Confrontación? ¿Mundos antagónicos? Nuñez prefiere y elige "dislocación" entre jóvenes y escuela, algo que, en sus palabras, no termina de encastrar pero de todos modos no es inviable que ocurra. Modos diferentes de pensar las mismas cosas, tensiones o incluso de culturas diferentes en la escuela y las culturas juveniles. Esto incluso es aplicable a la forma de reconocer la participación política, también allí existe una distancia entre la visión adulta y la juvenil.

Pero es en la "temporalidad" donde más en evidencia queda esta dislocación. De una vivencia juvenil del tiempo presente -inmediato, próximo, cons- 
Revista de la Escuela de Ciencias de la Educación, año 11, número 10, enero a diciembre de 2015. Páginas 283-286. ISSN 1851-6297. ISSN en Línea 2362-3349. Nuñez, PedRo: (2013) La Política en LA ESCUELA: Jóvenes, JUSTICIA Y derechos en el espacio escolar. Diego Beretta - Fernando Laredo

tante- se contrasta con la temporalidad ordenadora secuencial de la escuela. Esto incluye una puesta en crisis de la autoridad de la escuela y los docentes como única referencia de saber (y de poder), puesto que ésta y ellos tienen múltiples competencias.

La escuela hace frente entonces -y la frase "hacer frente" es parte de un desplazamiento en el que aún estamos- a un momento distinto y carece de respuestas. La escuela pretende formar ciudadanos, jóvenes que aún no pueden ser considerados como tal; pero recibe, no obstante, ciudadanos. Ciudadanos que a los 16 años votan (o por lo menos está permitido que lo hagan), ciudadanos con derechos específicos que cuando la escuela nació no eran siquiera imaginados, ciudadanos que poseen modos de participar diferentes a los que modeliza la vida adulta y sin embargo conquistan. Ciudadanos que hacen política de modo diferente al que nuestras tradicionales formas de participación conocían e incluso que se mueven en el límite de las formas de participación en que la propia escuela permite alojarlos, como ser los reconocidos Centros de Estudiantes.

Desde una mirada crítica y fundada, con un lenguaje ameno sin perder rigurosidad, la consulta de este trabajo permitirá a docentes, autoridades, investigadores e interesados en estos temas hallar nuevos aires, considerar otras miradas y explorar nuevas preguntas. Merece ser leído en clave abierta, invitándose a recorrer estas páginas acompasadas de experiencias situadas, de perspectivas teóricas, de interrogantes compartidos en que de uno u otro modo estamos todos/as involucrados. O como señala Nuñez, "el análisis de la socialización política juvenil en la escuela secundaria nos muestra que existen múltiples maneras de transitar por las instituciones en un mundo de incertidumbres. También enseña que los jóvenes despliegan prácticas políticas originales, ciertamente con mayor grado de inestabilidad que las producidas por las generaciones precedentes, pero que afianzan visiones de lo político que suponen no sólo desafíos al modo en que concebimos los fenómenos sociales, sino principalmente, anuncian transformaciones culturales por venir".

\section{Notas Bibliográficas}

(1) Ediciones La Crujía, Buenos Aires, Argentina. 
